\title{
Synergy in the co-cracking under FCC conditions of a phenolic compound in the bio-oil and a model compound for vacuum gasoil
}

Álvaro Ibarra ${ }^{\dagger}$, Roberto Palos ${ }^{\dagger *}$, José M. Arandes ${ }^{\dagger}$, Martin Olazar $^{\dagger}$, Javier Bilbao $^{\dagger}$, Hugo de Lasa ${ }^{\ddagger}$

${ }^{\dagger}$ Department of Chemical Engineering, University of the Basque Country UPV/EHU, PO Box 644, 48080 Bilbao, Spain

$\$$ Chemical Reactor Engineering Centre, University of Western Ontario, 1151 Richmond Street, London, Ontario N6A 5B9, Canada

(*) corresponding author: roberto.palos@ehu.eus

\section{A. SCHEME OF THE CREC RISER SIMULATOR REACTOR}

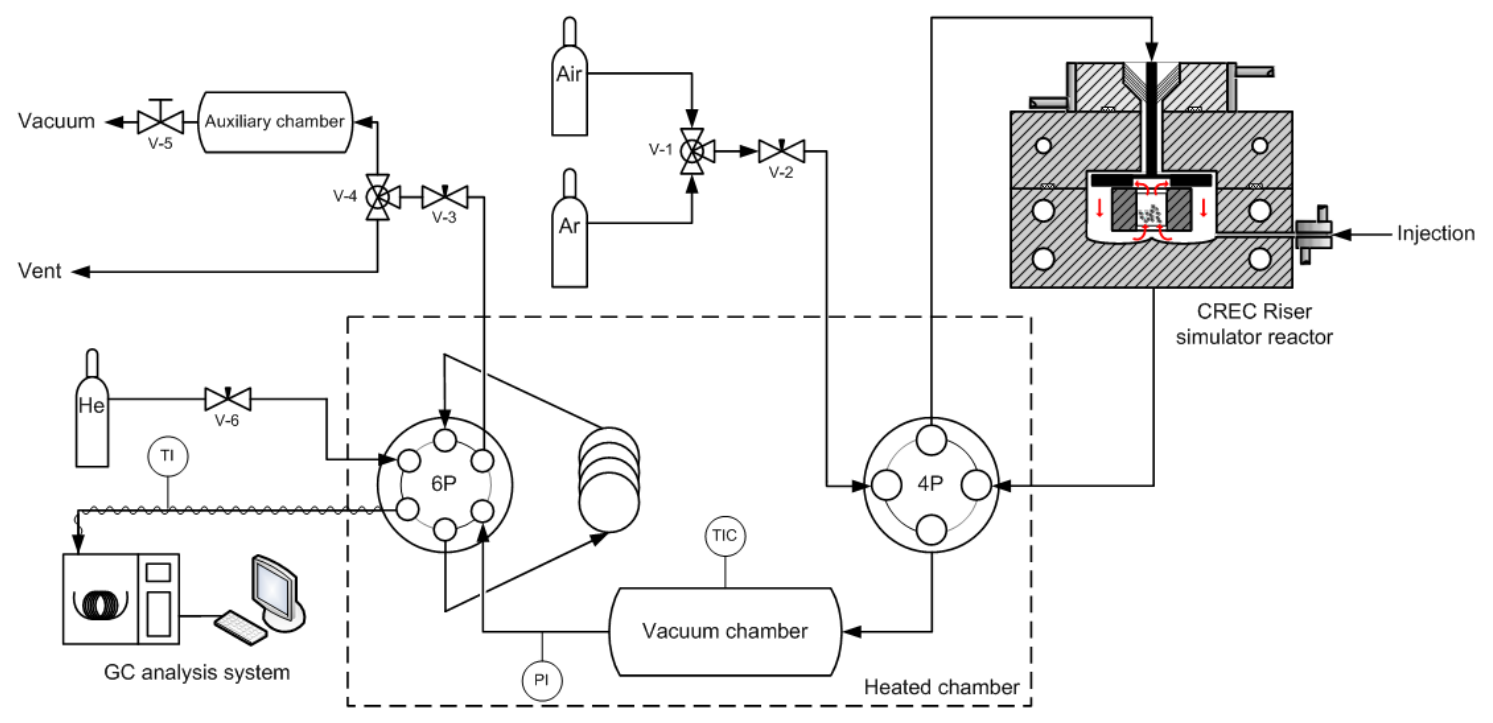

Figure S1. Schematic representation of the CREC Riser Simulator Reactor (De Lasa, 1992). 
B. YIELDS OF FRACTIONS IN THE CRACKING OF $\mathrm{C}_{16}$
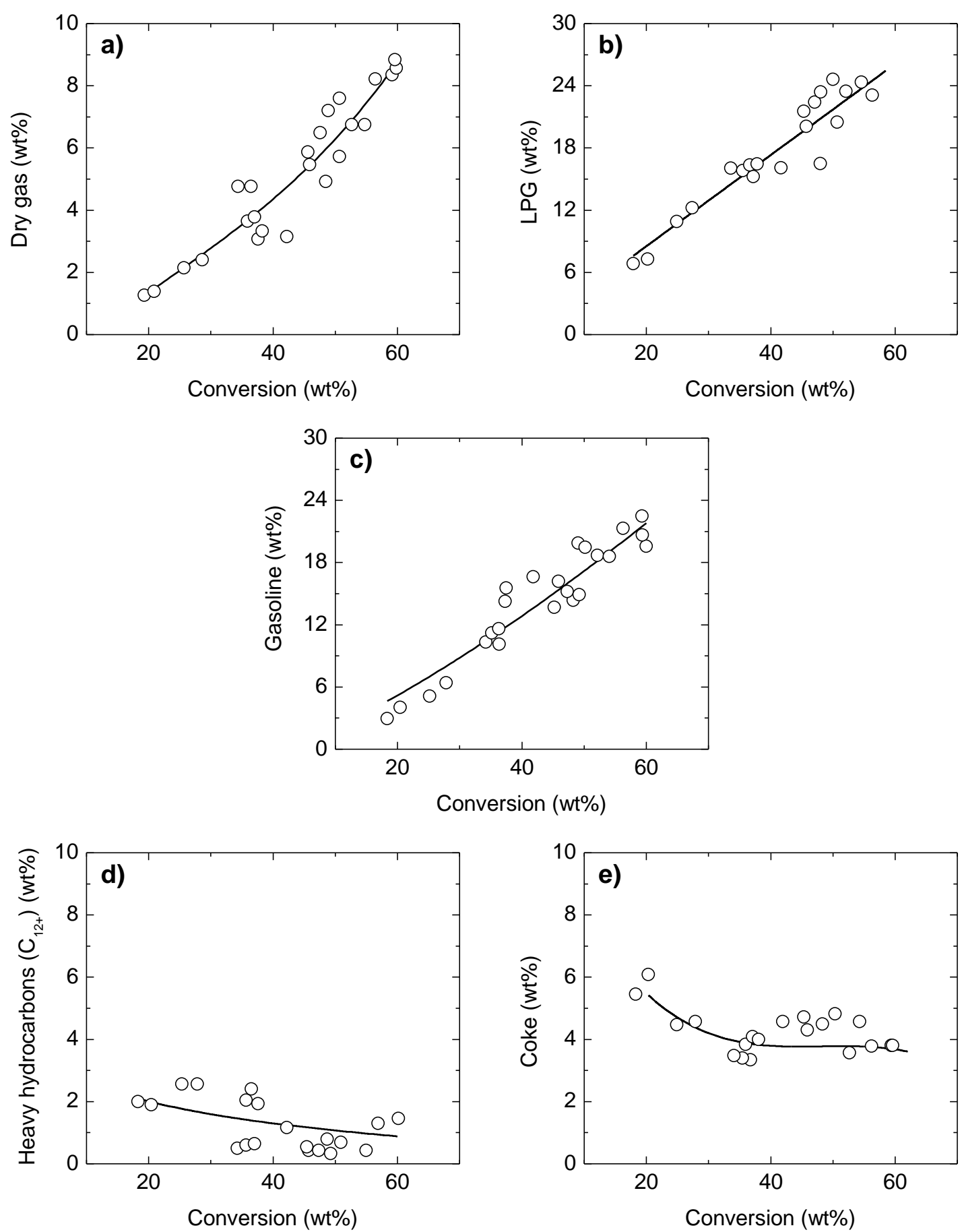

Figure S2. Effect of conversion on the product yields obtained in the cracking of $\mathrm{C}_{16}$ $\left(\mathrm{C} / \mathrm{O}=7.5 \mathrm{~g}_{\text {cat }} \mathrm{g}_{\text {feed }}{ }^{-1}\right)$. 